\title{
Pedagogía confuciana
}

PÍO GARCíA*

Artículo recibido: 18 de noviembre de 2013

Artículo aprobado: 5 de marzo de 2014

Doi: dx.doi.org/10.12804/desafios26.1.2014.02

Para citar este artículo: García, P. (2014). Pedagogía confuciana. Desafíos, 26 (1), 57-82. doi: dx.doi.org/10.12804/desafios26.1.2014.02

\section{Resumen}

El incentivo de la apreciación del capital resulta exacerbado en el intercambio global dominante, ya que supedita con mayor intensidad que antes al resto de los subsistemas sociales y altera la capacidad de recuperación del entorno ecológico. Las enseñanzas de Confucio vuelven a ser relevantes, dado su celo por garantizar la reproductibilidad constante de la familia humana por medio de la armonía social que resulta de la práctica de las virtudes personales y colectivas. La pedagogía familiar y social es indispensable para crear dicho círculo virtuoso.

Palabras clave: pensamiento asiático, educación, confucianismo, comunitarismo

\section{Confucian Pedagogy}

\begin{abstract}
The incentive for the appreciation of capital is exacerbated in the dominant global economy since it subsumes in higher proportions than before the rest of the social subsystems and alters the capacity for the recuperation of the ecological environment. In this context, the teachings of Confucius become relevant again, given his zeal to ensure the constant recreation of the human family through social harmony that

* Doctor en Filosofía. Docente e investigador de la Universidad Externado de Colombia, Bogotá. El artículo recoge las reflexiones suscitadas en el desarrollo del proyecto de investigación Pensamiento asiático, reconocido por Colciencias. Correo electrónico: piogarcia02@ yahoo.com
\end{abstract}


emerges through the practice of individual and collective virtues. The family and social pedagogy is essential in order to create this virtuous circle.

Key words: Asian thought, education, Confucianism, communitarism

\section{Pedagogia confuciana}

\section{Resumo}

$O$ incentivo da apreciação do capital resulta exacerbado em intercâmbio global dominante, já que submete de forma mais intensa que antes ao resto dos subsistemas sociais e altera a capacidade de recuperação do entorno ecológico. Os ensinamentos de Confúcio voltam a ser relevantes, devido ao seu zelo por garantir a reprodutividade constante da familia humana por meio da harmonia social que resulta da prática das virtudes pessoais e coletivas. A pedagogia familiar e social é indispensável para criar dito círculo virtuoso.

Palavras- chave: Pensamento asiático, Educação, Confucionismo, Comunitarismo

Tras un azaroso tránsito por las descalificaciones debidas a su carácter vetusto y reaccionario, las ideas del más célebre sabio chino se recuperan con aprecio inusitado. La forma como se restaura el pensamiento confuciano presenta múltiples vertientes. A medida que el Gobierno chino fue afirmando su injerencia en los asuntos globales, reivindicó un ideario distinto del liberalismo y el socialismo europeo. Su "socialismo con características chinas" postula el "ascenso armonioso" del país como aporte específico al acuerdo mundial futuro, en el que las tensiones protuberantes del presente estén neutralizadas. Al mismo tiempo, de manera paradójica, el rescate oficial del confucianismo refuerza la decisión de las autoridades chinas de ampliar su posición en la competencia global por medio del dominio técnico y científico, al punto que la excesiva inversión en un pequeño grupo de instituciones educativas aventajadas aumenta la distancia entre la élite de las universidades investigadoras y las instituciones de enseñanza común, con implicación incierta sobre la solidaridad nacional y el desarrollo 
y entre la inserción internacional y los desafíos de las comunidades locales (Mohrman, 2013). Este espacio local es, en cambio, un acicate para recuperar el confucianismo y asociarlo con la corriente filosófica comunitarista por parte de ciertos autores ${ }^{1}$.

Otra lectura contemporánea halla a Confucio a tono con las críticas posmodernas a la racionalidad positivista, individualista, esencialista y logocéntrica derivada del cartesianismo y forjadora de la modernidad europea. Desde esta perspectiva, la reciprocidad, el diálogo y la familiaridad en las relaciones humanas se retoman con gran estima. En tal sentido, dicho pensamiento debe ser entendido mejor como inter(dis)curso orientado a la vida práctica, en una red comunicativa extensa que asume al otro como ser completo, corporal y demandante de un trato ético: en esa dimensión ética, el ser y los valores se juntan y la acción adquiere su fuerza heterónoma, porque en ella siempre está presente el otro. Esta ética contrasta con la individualista o monológica predominante (Jung, 1993, p. 221).

En realidad, el pensamiento confuciano es menos oscurantista y sórdido de lo que ciertas críticas presentan de él; es menos gregario de lo que se piensa, aunque no por ello plegado al individualismo europeo. Su idea de la armonía social se aleja de la imagen de la colmena, en cuanto ella depende de la existencia de sujetos cultivados o educados, cuyo ser y su formación son el resultado del entramado de relaciones que los sobrepasan, pero al cual impactan con su propio comportamiento. El orden social corresponde a una estructura moral, heurística y de complejas relaciones de reciprocidad.

En concordancia con esta conjetura, el propósito del presente ejercicio es indagar los aportes de la doctrina confuciana a un paradigma de convivencia humana planetaria y cosmopolita, indispensable para detener la carrera hacia la posible desaparición humana del planeta Tierra. ${ }^{2}$ Me propongo argumentar que, frente al reduccionismo y el

\footnotetext{
1 Russell A. Fox (1997) está entre quienes se preguntan si Confucio fue un comunitarista.

2 De acuerdo con Brad Werner, un investigador de sistemas complejos, el capitalismo global ha hecho que la merma de los recursos sea tan rápida, fácil y libre de barreras que,
} 
derrotismo del concepto de sociedad de la modernidad —el modelo liberal- y su increíble separación de la esfera pública y la privada, la doctrina confuciana estructura un horizonte moral de mutuas responsabilidades y mutuo disfrute entre los seres humanos, en el que la continuidad entre el individuo, la familia y la sociedad es perenne, gracias a la capacidad aglutinadora de la educación. Para tematizar esos conceptos, parto de la caracterización del ordenamiento global contemporáneo y su soporte educativo y luego reviso el paradigma confuciano, cuya propuesta pedagógica instaurada sobre el arsenal de las virtudes cívicas procura la armonía colectiva donde esas mismas virtudes circulan y se expanden.

\section{Globalización y educación}

La doctrina confuciana ha sobrevivido a los avatares de la milenaria historia china y se ha hundido para levantarse luego sobre sus cenizas. ${ }^{3}$ En tiempos cercanos, ha tenido que sortear tres enjuiciamientos. El primero, con una enorme repercusión política, lo propinó la crítica de Mao a su carácter conservador, en cuanto aliada de las tradiciones familiares y de la preponderancia de las personas mayores en la organización política. El profundo arraigo popular a la estructura productiva y de relaciones señoriales — en la que la propiedad rural escindía el mundo rural entre los ínfimos clanes dueños de la tierra y las mayorías obligadas a trabajar para su beneficio, lo mismo que un aparato estatal aliado de ese favor particularizado que prescindía de las oportunidades de trabajo y bienestar colectivo- fueron el principal motivo de la revolución agrarista maoísta. A su modo de ver, esos valores feudales persistían aún después de la toma del Estado por el Ejército Rojo, en 1949, compuesto por campesinos desarrapados. Ante una gerontocracia inepta para resolver la inquietud popular y cobarde frente a las presiones del mundo externo, así como desafectada por las rigideces

en respuesta, "los sistemas tierra-humanos" se están volviendo peligrosamente inestables (Klein, 2013).

3 Fue prohibida en la época de la unificación imperial de Qin Shi Huang Di, en el año 321 a C. Luego fue adoptada como ideario oficial por la dinastía Han que lo sucedió y más adelante fue marginada durante la dinastía Tang, en una de las fases de mayor esplendor cultural. En el siglo XIII, el movimiento neoconfuciano de Wang Yangming renovó el orden político y social del Imperio del Centro. Su influjo se mantuvo hasta el siglo XX. 
del sistema soviético, Mao propugnó la revolución permanente o la reinvención del cuerpo político, que ponía en la línea de vanguardia al segmento idóneo para generar y llevar a la práctica las nuevas ideas, es decir, le abrió las puertas al ímpetu juvenil (Adler, 2011). Ese espíritu desbordado estremeció al máximo los pilares del pueblo chino, tal como se lo propuso su ideólogo, hasta retornar, en los años ochenta del siglo pasado, al reposo y al ensayo de nuevos arreglos políticos una vez esa energía pudo ser desfogada. Tal vez si China no hubiera pasado por ese período de enconado anticonfucianismo no hubiera revivido el fervor por los cánones de la armonía y las virtudes ciudadanas que enarbola la dirigencia de Beijing hoy día.

Un segundo objeto de crítica a Confucio y su mensaje está ligado también al rechazo a la tradición. El desprecio por el pensador tiene que ver, esta vez, con la idea de respeto irrestricto a la autoridad, entendida como el resultado de esa confabulación entre el orden familiar y el orden político, porque el adiestramiento del carácter servil empezaría por el sometimiento sagrado al principio de la "piedad filial", amplificado después a la esfera institucional del Estado. Los gobernantes tendrían plenas garantías para su despotismo y las formas inimaginables de ejercicio arbitrario del poder al quedar incontrolada su conducta, ya que la capacidad de reacción popular estaría inhibida por la reverencia rastrera. Los analistas políticos encuentran ejemplos numerosos de este tipo de Estado en Asia y achacan su autoritarismo a la huella confuciana en la región (De Bary, 1984; Sim, 2001).

De no menor importancia es el descrédito del gregarismo y el colectivismo confuciano. Al ubicar en un lugar tan central a la familia y a los intereses de la sociedad, esta enseñanza barre — según sus críticoscon la conquista del individuo como sujeto del acuerdo político, visto este como el mayor resultado de la modernidad que Europa extendió por el planeta. Los países de influencia confuciana tendrían considerable hostilidad a los logros personales, a la competencia intersubjetiva, al dominio privado y a la responsabilidad subjetiva, porque en ellos se imponen los intereses objetivos y colectivos. Por lo tanto, se trataría de sociedades muy adecuadas para las tareas de grupo, la producción industrial masiva y otras bondades de la producción manufacturera, 
pero impedidas para la creación de tecnologías y la innovación, que requieren destrezas más individualizadas. En consecuencia, no sin envidia, ciertos analistas del desarrollo económico consideran que, sin su actitud gregaria, los países asiáticos no hubieran podido industrializarse. En consonancia con la crítica del autoritarismo, los juzgan pueblos duales: con visible modernidad industrial, pero atrasados en la discusión pública. Los denominan "democracias no liberales" (Fox, 1997), por las restricciones a las libertades políticas de la escuela anglosajona. Esta ciudadanía de segunda estaría haciendo realidad el eslogan japonés del siglo XIX: tomar de los europeos solo sus avances técnicos y aferrarse a su valores milenarios sintoístas y confucianos, razón última de su éxito industrial. Estos valores aceitan así la inequidad mundial. En consecuencia, superar los diversos efectos colaterales de una máquina productiva globalizada y deshumanizada es el gran desafío del confucianismo hoy.

Sin duda, el hombre que dijo "aprender sin pensar es inútil; pensar sin aprender es peligroso" (Confucio, 1995, p. 12) 4 adquiere vigencia en el campo educativo. Su legado ético ofrece indicaciones sugestivas para las estrategias alternativas al paradigma dominante de una globalización con alto contenido autodestructivo. La larga vida del maestro Confucio (Kongæi, 孔子: maestro Kong) quien, al parecer sin mucha asistencia médica, alcanzó los 82 años, comprendió un proceso de reflexión y enseñanza dirigido a conmover las visiones del mundo y las instituciones de su época. En un tiempo de guerras brutales entre pueblos hermanados, durante los siglos VI y V a. C. en plena barbarie de los "Estados combatientes" antes de la unificación imperial china, levantó su voz a favor de la solución racional, magnánima y justa del conflicto social y político. Su doctrina no parece alejada de la búsqueda actual de remedios a la pugna entre los Estados, la lucha por el control del poder económico y político, la intransigencia, el racismo, la violencia intrafamiliar, la criminalidad en las grandes ciudades o el matoneo en los centros educativos.

\footnotetext{
4 Confucio compiló el conocimiento de su tiempo en los cinco libros clásicos: El libro de los cambios - I Ching - El libro de los documentos, Las odas, El ceremonial y los Anales de primavera y otoño. Sus discípulos compendiaron su pensamiento en cuatro obras, a saber, Las analectas, La gran enseñanza, La doctrina del Medio y Mencio.
} 
Sabemos que el debate educativo se halla en el corazón de la controversia sobre el intercambio global. Los tiempos que vivimos corresponden a la fase avanzada - para algunos, postrera - del sistema económico (Wallerstein, 1974), cuando empujados por la lógica implacable del mercado tenemos que disputar la sobrevivencia de una manera atroz. Atraídos por el imán de la acumulación capitalista, nos vemos constreñidos a emplearnos a fondo y quien no entra en la puja no es más que un ente improductivo, un desadaptado social, un desecho. Lo extraño es que la producción incesante de la escoria del desempleo y el subempleo es esencial en el mecanismo que sostiene la apreciación de las inversiones, porque, para evitar caer en el ejército de reserva, el trabajador se esmera por elevar la productividad (Marx, 1975, p. 13). El portentoso logro de la subjetividad moderna, ese del individuo soberano que se hace sujeto, realiza tal condición en sentido literal, al quedar constituido en triple sujeto, pues queda bajo el mando de tres patronos, a falta de uno: el inversionista, el Estado y la mano invisible del mercado global. Este último surge como un dios mucho más trascedente y poderoso que ese dios feudal y premoderno, al que la llegada de la técnica echó por la borda. El resultado final es el absurdo de un mundo que acumula los excesos del capital, las mercancías y el desempleo, mientras el ecosistema planetario se resiente cada día más, con riesgo de su reproductibilidad (Dierckxsens, 1981). ¿Deben ser la productividad y la eficiencia, por sí solas, el parámetro que determine los planes educativos o han de ser criterios integrados a otros valores de incidencia social? ¿Qué enseñanzas pueden ofrecer a la vida contemporánea las tradiciones de pensamiento ajenas al marco valorativo dominante de corte anglosajón? ¿Cómo puede la doctrina confuciana propiciar el círculo virtuoso de la bondad individual y colectiva, más allá del patrón contractual dominante? Nada más lejano al ideario confuciano que un mundo subalterno del capital, donde la gente no es dueña de su destino y el esplendor de la vida humana y la naturaleza son el precio a pagar para sostener la corriente de la producción per se.

Desde diversos ángulos teóricos, la educación resulta hoy día sometida a crítica y se ensayan nuevas propuestas pedagógicas. El modelo tradicional docente centrado en la memorización de los contenidos ha sido abandonado en forma progresiva, para dar paso a prácticas más 
flexibles, abiertas y enfocadas ya no en el maestro omnisciente, sino en el desarrollo de las capacidades del estudiante. El proceso educativo tiende a ser visualizado como una secuencia de etapas por medio de las cuales los alumnos superan las competencias inconscientes con las fases de apropiación consciente de estas, entendidas como habilidades múltiples cognitivas y operativas. En las etapas iniciales, el individuo no sabe que ignora, no es consciente de su déficit de conocimiento; una vez percibe su incompetencia, valora la adquisición de nuevas destrezas hasta llegar a contar con aquellas adquiridas, al modo de una "segunda naturaleza" por la que eleva su desempeño profesional (Bartram, 2005; Boud, 2000; Hayton, 2006; Maslow, 1943). Al ser observables, las competencias son susceptibles de ser medidas y valoradas. Aunque no hay un consenso sobre el alcance del concepto, se impone hoy la teoría pedagógica del entrenamiento basado en las competencias que el individuo se esmera en alcanzar, para insertarse de manera exitosa en la ardua competición laboral, donde vale su pericia operativa más que las anteriores pruebas de inteligencia (Gulikers, 2009). Estas premisas refuerzan la alianza Estado-universidad-empresa (McClelland, 1973) con el fin de potenciar el aparato productivo de los países.

En una dirección opuesta a la tendencia pedagógica del entrenamiento para el cumplimiento pasivo de las tareas asignadas en un sistema productivo autopropulsado, se suele destacar la necesidad de dar autonomía al sistema educativo, con el fin de realzar las capacidades críticas y creativas de los formados, pues diversas instituciones de la sociedad se ven destruidas cuando la educación es mercantilizada (O’Dwyer, 2001). A su modo de ver la situación, las competencias individuales sobreestimadas en el parámetro liberal deben ser contrarrestadas por un tipo pedagógico que reafirme la primacía de la vida colectiva y el contexto ético de las relaciones humanas. ${ }^{5}$ Los reproches se enfocan, con frecuencia, al control del sistema educativo con criterios cuantita-

\footnotetext{
5 Apartada del modelo de las competencias individuales, la teoría de las competencias colectivas insiste en la necesidad de apreciar los eventos laborales como fenómenos colectivos, desarrollar y aprovechar el conocimiento colectivo y acrecentar la conciencia de la interdependencia de los individuos (Boreham, 2004).
} 
tivos por parte de una élite burocrática aliada con los legisladores, que replica de manera descontextualizada algunas pruebas piloto de corte evaluativo y científico. En este sentido, Mehta (2013, p. 479) reclama - para el caso estadounidense - reformas del sistema educativo en las que, mediante una alta influencia del Estado - como en Corea o Singapur-, se establezca una complementariedad de la educación con el resto de aspectos de la sociedad, para superar la adecuación rutinaria al control burocrático propio de la Era del Progreso, que uniformó la actividad educativa con el tipo fabril taylorista a comienzos del siglo $\mathrm{XX}$. Al respecto, se debe anotar que la pedagogía confuciana no descalifica la ciencia y el mejoramiento técnico, pero se opone —al igual que las anteriores críticas - al reduccionismo económico; asimismo, comprende la mutua implicación de las instituciones sociales -incluido el sistema educativo- y la continuidad de los logros personales, con los familiares y los sociales, como hemos de ver enseguida.

\title{
El talante moral del hombre superior
}

El ideal de vida confuciano estatuye la realización individual en una vida prolongada y acuciosa, de tal modo que, al final, en esas personas "sus palabras alcancen una mayor excelencia". Ese "largo camino" (Confucio, 1995, pp. 66-67) describe una secuencia de superación de sí mismo:

\begin{abstract}
A los quince años, mi voluntad se aplicaba al estudio; a los treinta estaba firme; a los cuarenta no tenía dudas; a los cincuenta conocía el Mandato del Cielo; a los sesenta podía escuchar las verdades sin dificultad; a los setenta podía seguir lo que mi corazón deseara, sin hacer el mal (Confucio, 1995, pp. 9-10).
\end{abstract}

Vivir la vida se convierte para cada uno de nosotros en un desafío cognitivo y anímico permanente, que busca comprender las leyes de la naturaleza - el tao o el camino- con el fin de juntarlos y contrastarlos con las tradiciones, dado que ellas son sabiduría acumulada. Crecer en la sapiencia implica asumir ambos conocimientos: el científico y el ancestral; de ahí que Confucio asevere: "Yo no nací sabiendo; a mí me gusta la antigüedad y en ella investigo con diligencia" (Confucio, 1995, p. 46). 
Observar y aprender siempre de todos se convierte en una tarea primordial reveladora del interés personal por ampliar el conocimiento, como la ruta ardua y abnegada de la autorrealización. Es por eso que, como maestro, Confucio no descubre "las verdades a quien no está deseoso de descubrirlas" ni hace salir algo que "la propia persona no quiera exhalar" (Confucio, 1995, p. 44). ${ }^{6}$ Cualquier semejante es digno de constituirse en maestro, siempre y cuando personifique alguna forma de la virtud: "Cuando somos tres los que marchamos juntos, los otros dos pueden ser mis maestros; tomo de ellos sus buenas cualidades y las sigo, mientras evito las que tengan malas" (Confucio, 1995, p. 47). Prácticas como el respeto al otro o la reverencia a los antepasados están condicionadas, entonces, por la bondad que contengan, porque no se deben aceptar de manera automática, pues "la benevolencia tiene que proceder de uno mismo, no puede proceder de los demás" (Confucio, 1995, p. 79).

La contextura moral del ser humano superior está dirigida por el estudio y la disciplina y se enriquece con los atributos del arte y de la sensibilidad, más allá de la simple complacencia intelectualista: "No me basta llegar a ver un sabio, me bastaría con ver a un hombre superior" (Confucio, 1995, p. 47), porque "antiguamente, los hombres estudiaban en orden a perfeccionarse a sí mismos, ahora estudian para que los vean los demás" (Confucio, 1995, p. 100). El arte cumple ese papel de ampliar el conocimiento y enriquecer la vida, en cuanto "la mente se despierta con la poesía. Se afirma con los ritos. Se completa con la música" (Confucio, 1995, p. 53).

Es frecuente deducir que el énfasis del confucianismo en la familia, el grupo y la armonía comunitaria clausura las prerrogativas individuales, un rasgo tan fundamental de la civilización contemporánea, pero el cuerpo social del pensador chino es todo menos una masa informe. Los seres humanos alcanzan diferentes grados de individuación o

\footnotetext{
6 Por eso, "un hombre superior, cuando come no pretende hartarse, ni en su casa busca estar tranquilo y despreocupado; es diligente en los asuntos, pone cuidado en sus palabras y busca a los que poseen la doctrina para que lo rectifiquen. De un hombre así es de quien puede decirse que es alguien que ama el estudio" (Confucio, 1995, p. 4).
} 
distanciamiento del agregado colectivo, en cuanto logran escalar a los niveles más elevados de la pirámide social gracias a su atributo moral, porque llegan a ser las personas más rectas.

Hoy día, en contra de las ideas populares de la democracia y la igualdad de derechos, vivimos en sociedades muy escalonadas, pero no en una jerarquía de menor a mayor probidad, benevolencia y valentía, como enseñaba Confucio, sino a partir de la urdimbre de los intereses económicos y políticos que actúan en inquebrantable asocio. Así, quien más dinero reúne acrecienta las posibilidades de poner a su servicio a la organización administrativa, que opera según los dictados de la acumulación. El negocio señorea y construye un margen de libertades políticas y programas de bienestar social solo en la medida en que ellos pueden quedar dispuestos a la rentabilidad del capital. Con tal de llegar a ese fin, se validan las guerras, la traición, el agiotaje, el engaño, la esclavitud, la servidumbre y las formas más abyectas de conducta. No sin razón, la "democracia" no solo es objeto de sospecha sino de odio (Rancière, 2006). La jerarquía confuciana encumbra, en cambio, a los individuos que acumulan en su vida — mediante la práctica constante- el estudio y las virtudes morales de la disciplina, la paciencia, la solidaridad, la benevolencia y la valentía (Confucio, 1995, p. 122).

Rancière ha elaborado una crítica recia al discurso liberal que separa el mundo de los sabios y los ignorantes, para justificar el dominio de los primeros sobre los segundos, lo mismo que al populismo del rescate de los no educados por los educados, que genera la dependencia infinita del rescatado hacia su rescatador. Contra un sistema productivo que se alimenta de la estultificación, este autor pone la premisa de la sabiduría connatural a todos los seres humanos y su correspondiente efecto político de igualdad como punto de partida y no como objetivo político (Rancière, 2010). Pareciera un golpe recio al mundo jerarquizado confuciano también, de no ser porque está ubicado en una dimensión distinta: la del escalonamiento moral y el orden ético, no economicista, de la comunidad política. 


\section{La antropología relacional}

El tipo de individuo fundador del orden moderno capitalista es el sujeto monádico lutero-cartesiano (De Gregori, 2011, p. 27). El yo puede autofundarse, porque se entiende como el único interlocutor válido con Dios, ya que no necesita mediadores que le expliquen el mensaje de las Sagradas Escrituras. Ese yo autosuficiente ha de tomar distancia de los otros, como condición para establecer el ejercicio intelectual sobre el cimiento de la idea clara y distinta del "pienso, luego existo" (Descartes, 1981). La experiencia subjetiva adquiere el rasgo de un acto de fe, una pura presunción espiritual cuya pureza es proporcional a la distancia respecto al dato externo y la influencia contaminante de los otros.

La comprensión de la individualidad confuciana es de igual modo una experiencia, pero muy distinta a ese solipsismo o "subjetivismo metodológico" desvalorizado por Taylor (1997) y Tugendhat (1998), que construye el mundo desde el sujeto aislado o "la mónada sin puertas y ventanas", de Leibniz (1983). En el confucianismo, el ser se convierte en un ejercicio relacional, próximo al movimiento intelectual que toma distancia del cartesianismo (Morin, 2000). La existencia individual ocurre dentro de un haz de vínculos sociales preexistentes que la determinan; su margen de acción es amplio, pero jamás puede sobreponerse a ellos. La creatividad y la libertad son posibles solo como la elaboración posterior sobre la conciencia y la experiencia de esos trazos del tejido social.

La individualidad confuciana está acoplada a la sociedad mediante cinco vínculos primordiales, a saber: gobernante-gobernado, padrehijo, esposo-esposa, hermano mayor-hermano menor y amigo-amigo (Confucio, 1995). Cada ser humano es un sujeto atado por esos nexos en los cuales queda inmerso al llegar al mundo; ellos lo definen, pero le dejan suficiente campo de maniobra para el ejercicio de su libertad posible, ya que ella no es absoluta. Así, puede pasar de ser hijo a ser padre, de gobernado a gobernante, a esposo o esposa y a rodearse o no de amigos; sin embargo, su condición de hijo y de hermano mayor o menor son inamovibles, con las obligaciones que ello comporta. El conjunto político no es un agregado compuesto por piezas sueltas, 
sino una familia extensa $(\mathrm{Hu}, 2007)$ con sus afectos, defectos, roles y posiciones en vínculos que generan afinidades y discrepancias.

Como se trata de relaciones, las partes se definen de manera mutua, así que no se presenta el binomio padre-madre sin el hijo y los hijos determinan la naturaleza de los padres, del mismo modo que el gobernante lo es como referido de sus gobernados y los amigos por el circuito que se establece entre ellos. El líder político se define por el acatamiento de su autoridad moral: "Cuando un gobernante es recto se pondrán las cosas en práctica aunque no de órdenes" (Confucio, 1995 , p. 89). Por tanto, las relaciones sociales son verticales, transversales y horizontales y tienen como denominador común su reciprocidad, porque un punto remite por necesidad a otros nodos de la red social.

Las orientaciones actuales de la teoría de la motivación educativa por logros estipulan el carácter relacional del proceso pedagógico en un sentido muy cercano a la antropología confuciana y ponen de manifiesto el interés que suscita esa doctrina milenaria. Dicho marco conceptual vincula entre sí al estudiante, al profesor, al salón de clase y a la institución educativa dentro de un conjunto dinámico, en el que "las relaciones positivas con los significantes otros son piedras angulares para capacitar a la juventud su desempeño social, afectivo y académico" (Martin, 2009, p. 351). En Confucio, empero, la relacionalidad está inscrita en el dominio ontológico, ya que sin ella el ser humano no existe; se remonta más allá del carácter de la relacionalidad estratégica de la integración social. Ser es aprender a conducir un tipo especial de existencia moldeado por la virtud, que lleva a exigir las condiciones requeridas por parte de la familia y la comunidad política. Asimismo, el sentido correlativo de la relacionalidad de la subjetividad es la posición sobresaliente de la dialogicidad en los asuntos familiares y colectivos (Jung, 1993).

\section{Virtud y educación}

Para Confucio, la educación es un trabajo personal de toda la vida, pero no es una rutina espontánea. Ese ser relacional que es el sujeto empieza su historia particular como un objeto de las vivencias y las enseñanzas de sus padres, maestros, hermanos, gobernantes y amigos. 
La persona tiene nexos con las demás personas, por el hecho de vivir en sociedad. De eso se trata la experiencia social: de interactuar con los otros. Sin embargo, el calibre de esos nexos varía según la posición que el otro ocupe dentro de la estructura, de manera que no es el mismo tipo de trato con las personas mayores que han acumulado más experiencia - y se supone que más virtudes — que con aquellas a quienes precedo y esperan más enseñanzas de mi parte. Por ejemplo, así como aguardo protección de los hermanos mayores, he de estar dispuesto a brindársela a los menores y cuando los mayores, por edad avanzada, requieran de mi cuidado, he de actuar en reciprocidad a la protección recibida. La mayor fortuna de alguien es contar con modelos positivos a replicar, porque "el hombre superior tiende a perfeccionar lo bello del ser humano y a abandonar lo malo de él. El hombre vulgar hace lo contrario" (Confucio, 1995, p. 83).

Individuarse o graduarse como individuo es la tarea del ser humano, con el fin de ascender a las posiciones sobresalientes del ser superior o el ser virtuoso depurado. Dentro de un evidente razonamiento triádico semejante al paradigma de la proporcionalidad que prepondera las inteligencias lógica, emotiva y operativa (De Gregori, 2011), el desafío ético confuciano reta a calificarse en las tres virtudes fundamentales: la sabiduría, la benevolencia y la valentía (Confucio, 1995, pp. 63, 101, 127). La primera realza la inquietud intelectual del pensar-aprender o del desarrollo de las distintas disciplinas del conocimiento teórico. El estudio de los libros es una parte indispensable, pero requiere el complemento de la experiencia. Para Confucio, es incomprensible la sabiduría precoz (Confucio, 1995, p. 32), como imposible la unión de la ignorancia y la virtud.

La segunda virtud capital tiene que ver con el espíritu humanitario o la sensibilidad preparada para desencadenar el reconocimiento del otro. En este sentido, no puede haber virtud en la indiferencia, como lo pretendían los taoístas, alejados de las peripecias que ofrece la vida compartida con los demás seres humanos y quienes, para escaparse de esas contingencias, se refugiaban en los montes, "lejos del mundanal ruido". La más elevada forma del amor es ese lazo afectivo que los padres crean en los hijos, mostrado como la "piedad filial", capaz de 
tolerar incluso el rigor de su conducta: "El que sirve a su padre y a su madre puede quejarse de ellos con moderación. Si vieran que no siguen lo que él desea, les servirá con todo respeto, pero sin contravenir el propósito original y sin quejarse aunque le castiguen" (Confucio, 1995, p. 32). Por supuesto, siempre y cuando los padres, mayores o los gobernantes no se sobrepasen en injusticias manifiestas.

De no menor importancia es la disciplina personal y el arrojo como virtudes. El control de sí, "el autodominio y la insistencia en los ritos es lo que tendrá como resultado la benevolencia” (Confucio, 1995, p. 79). El autogobierno supone la disciplina, el trabajo arduo y el poder para resistir el dictamen injusto, la deshumanización y el ultraje. Reaccionar contra los hermanos mayores, padres o gobernantes arbitrarios no es una simple opción, sino un deber moral en la doctrina confuciana, porque la resignación es opuesta a la valentía. Para el sabio chino, la rebelión y la guerra justa son válidas y en su nombre se alzaron movimientos de repudio a los excesos imperiales, porque "ver la justicia y no hacerla es cobardía” (Confucio, 1995, p. 14).

Es primordial establecer el carácter tendencial y emotivo de las virtudes (Wang, 1999; Wang, 2008), pues dicho presupuesto teórico se convierte en la premisa de la regla del justo medio; según esta, la virtud es el término medio entre los extremos de lo aportado por la naturaleza y lo creado por la cultura, porque:

Cuando las cualidades naturales se imponen sobre las que da la educación, el sujeto en cuestión será un rústico; cuando lo aprendido domina a lo innato, el individuo de que se trate será un vulgar funcionario; cuando lo natural y lo que deriva del estudio están armoniosamente mezclados es cuando nos encontramos ante un hombre superior (Confucio, 1995, p. 7).

La pluralidad de las virtudes y la referencia a la ubicación del justo medio no es un acopio obtenido de manera espontánea, caso en el que la cultura y la educación estarían de más; sin embargo, tampoco son simple construcción artificial, como si estuvieran impresas en la tabula rasa. Son la composición justa de la trasformación del dato 
animal para humanizarlo, por medio de la sabiduría colectiva. Los impulsos humanos tienden a desencadenarse y opacar el intelecto, de modo que eliminarlos no es una solución definitiva, sino su acomodo y regulación que impone la sabiduría, puesto que "si surgen, pero están equilibrados, se dice que hay armonía. El Medio es la raíz principal de todo lo que hay bajo el Cielo; la armonía es el gran objetivo del mundo" (Confucio, 1995, p. 340).

Las virtudes se erigen como coordenadas que iluminan la acción en su triple motivación - emotiva, operativa y cognitiva - y en su dependencia mutua, en cuanto el apego al estudio da el conocimiento, la práctica de la virtud anima la benevolencia y la vergüenza acerca la valentía (Confucio, 1995, p. 350). A su vez, la regla de oro discrimina los efectos de la acción:

$[\ldots]$ hay tres clases de amistad que reportan beneficio y otras tres que son dañinas [...]; hay tres clases de placeres beneficiosos y otros tres que resultan perjudiciales [...]; hay tres faltas que pueden cometerse cuando se está en presencia de un hombre de saber y posición. ${ }^{7}$

El justo medio establece la guía para interpretar lo que es debido hacer: "lo correcto" en un momento dado (Fung, 1976, p. 173); es un criterio más cualitativo que cuantitativo. Como en Aristóteles (2003), el disfrute del conocimiento cumple una función rectora: en el filósofo griego, porque la contemplación intelectual corona la pirámide de las virtudes y, en Confucio, por el hecho de despejar el espacio de la justicia, la virtud primordial en su arquitectura política: "el hombre superior pone a la justicia en el lugar más alto” (Confucio, 1995, p. 127).

\footnotetext{
7 De manera específica, "es beneficiosa la amistad con los rectos, con los honestos y con los que han oído y saben muchas cosas. Es dañina la amistad con los hipócritas, con los aduladores y con los que hablan hábil y tortuosamente [...]. Producen beneficios el placer de la música y el de las ceremonias comedidas, el que causa hablar acerca de las excelencias de otros hombres y el de tener muchos amigos de mérito. Son perjudiciales: el gusto por las diversiones lujosas y extravagantes, el complacerse en la pereza y el deleitarse en festines disolutos". Ante el hombre superior, son faltas "hablar cuando no se debe, que es exaltación; no hablar cuando se debe, que es ocultación, y hablar sin mirar la actitud del rostro de superior, que es ceguera" (Confucio, 1995, pp. 117-118).
} 


\section{Educación y globalización armónica}

Debido al hecho de que el actuar ciudadano no conlleva una virtud sino un conjunto de ellas, se crean unos contrapesos éticos de enorme importancia para entender las prerrogativas individuales y su relación con el desempeño intersubjetivo. La rebelión política, por ejemplo, dictada por la necesidad de combatir situaciones degradantes del ser humano por efecto del apremio de justicia, ha de estar acompañada de la sabiduría y de la benevolencia, para que tenga éxito y para evitar los excesos, ya que tras el empeño de acceder a lo justo se pueden cometer injusticias colaterales. El paradigma confuciano encuentra su motivo central en el cultivo de esa pluralidad de las virtudes, puesto que gracias a él la subjetividad compone su identidad y la sociedad entrelaza a sus miembros. La organización política puede ser entendida en un sentido agregativo, pero no de la suma aritmética de los habitantes sino en una especie de suma geométrica del capital humano, representado por la acumulación de las virtudes de todos los participantes.

¿Cuál puede ser el referente para el individuo en el cumplimiento de su papel en la sociedad, a sabiendas de que desea intensificar su patrimonio moral con la práctica de las virtudes? Es lógico que no todo el mundo tenga que hacer lo mismo, porque la sociedad es una estructura compleja de géneros, edades y culturas diversas, que llevan a cabo actividades múltiples. Viene aquí una disertación semiológica de notable originalidad por parte de Confucio, como su teoría de la rectificación de los nombres:

Si los nombres no son correctos, las palabras no se ajustarán a lo que representan y, si las palabras no se ajustan a lo que representan, los asuntos no se realizarán. Si los asuntos no se terminan, no prosperarán ni los ritos ni la música; si la música y los ritos no se desarrollan, no se aplicarán con justicia penas y castigos y, si no se aplican con justicia penas y castigos, el pueblo no sabrá cómo obrar. En consecuencia, el hombre superior precisa que los nombres se acomoden a los significados y que los significados se ajusten a los hechos. En las palabras del hombre superior no debe haber nada impropio (Confucio, 1995, p. 88). 
Entre los individuos, la familia y la sociedad no hay discrepancias ontológicas o valorativas, puesto que son esferas congruentes del círculo de la virtud. Sin embargo, existen diferencias funcionales entre esas instancias, determinadas por los nombres que portan. El lenguaje instituye el ser y humanizarse es actualizar el nombre de lo que alguien es y que hace; su palabra vale porque es efectiva. A cada ser le corresponde un nombre y por eso lo designamos de una forma específica: planta, animal, astro, luz, energía. En el ámbito social, cada individuo, enganchado como está en ese haz de relaciones, posee un oficio, se ocupa de algo, cumple con una tarea. Lo que debe hacer no es ni más ni menos que lo que corresponde a eso que de él esperan los demás: darle contenido a un nombre. Si es padre, cumplir con el oficio paternal; si es hijo, con los deberes filiales; si es agricultor, desempeñarse del mejor modo posible en ello; si es médico, arquitecto, contador o gobernante, hacerlo con el mayor grado de excelencia posible.

De manera opuesta al ideario liberal, las instituciones no son las barreras que impiden la natural eliminación de los seres humanos entre sí, sino la amplificación del equilibrio personal y familiar que se eleva a la excelencia, en tanto ese orden le es más favorable. El gobernante, cuyo oficio porta la máxima responsabilidad dado el cuidado del conjunto social que sobrelleva, es quien más educado y virtuoso ha llegado a ser, no quien más pregona o promete serlo. El rey-sabio, como en Platón, lo es porque ostenta la moralidad excelsa, propia del nombre particular del ejercicio de gobernar, de modo que la autoridad que lo inviste es ética, no del monopolio de la fuerza. Así como se aparta del ascetismo taoísta, el confucianismo también se aleja del rigorismo de la escuela legalista que amparaba la constricción de la gente en nombre de la ley. El buen gobierno consiste, por tanto, "en que el soberano sea soberano, el ministro, ministro, el padre, padre y el hijo, hijo" (Confucio, 1995, p. 82).

Ahora bien, el gobernante debe ser el mayor dechado de virtudes, de modo que no basta con poseer cierto grado de benevolencia o de valentía, sino del conjunto virtuoso en grado sumo. Ello quiere decir que debe haber manifestaciones empíricas de su gestión, como la vida virtuosa del pueblo, de la cual forman parte la sabiduría y la 
benevolencia tanto como el bienestar material. En efecto, "si los que ocupan puestos superiores gustan de los ritos y ceremonias, el pueblo no se atreverá a ser irrespetuoso, si gustan de la justicia, el pueblo no se atreverá a desobedecer, si gustan de la sinceridad, el pueblo no se atreverá a no ser sincero" (Confucio, 1995, p. 88).

El gobernante no puede ser sino un hombre superior excepcional, con las cualidades morales suficientes para constituirse en el padre de la familia extensa que es la comunidad política. Por su estatus sobresaliente es reconocido como el "hijo del cielo", del tien, o sea, quien por su conocimiento, bondad y acción logra emparentarse con la ley natural, con la regularidad del universo, quien mejor sabe por qué "las cuatro estaciones se suceden y por qué las cosas nacen" (Confucio, 1995, p. 126). Descifrar lo arcano lleva a conocer también lo humano y, en cuanto dueño de la pluralidad de virtudes, ha de estar en capacidad de mostrar resultados mediante la debida administración política:

[...] el que no sabe cuál es el mandato del cielo, no puede ser un hombre superior; el que no conoce los ritos, no puede ser un hombre de firme carácter; el que no sabe el significado de las palabras, no puede conocer a los hombres (Confucio, 1995, p. 143).

Poco importa, entonces, el mecanismo que una sociedad utilice para nombrar a sus gobernantes, sean procedimientos de herencia o de elección; lo cardinal es la autoridad moral que puedan demostrar esos ciudadanos. ${ }^{8}$

El ejercicio político confuciano está orientado a la maximización de la virtud ciudadana con el acompañamiento del gobernante-maestro, experto en el tao que conduce al Cielo — tien—, a la armonía, porque "el hombre vulgar no conoce los mandatos del Cielo y por eso no los teme, es irrespetuoso con los grandes hombres y se mofa de las palabras de los sabios" (Confucio, 1995, p. 118). Como responsable del

\footnotetext{
8 Ello debido a que "si un hombre se corrige a sí mismo, ¿qué dificultad tendría para ejercer las labores de gobierno? Pero, si no puede hacerse recto a sí mismo, ¿cómo hacer que los demás lo sean?” (Confucio, 1995, p. 90).
} 
mejoramiento colectivo, no puede dejar de estudiar: "El que ocupa un cargo público debe dedicarse al estudio en sus momentos de descanso" (Confucio, 1995, p. 136), pues ampliar el conocimiento del tao es reforzar las demás virtudes. En este sentido, el gobierno humano es el arte de la sabiduría aplicada que, gracias a la orientación del justo medio, replica la armonía universal y la propia armonía personal en la esfera de la comunidad política. De esa manera, la continuidad virtuosa del individuo se halla en un movimiento de acción y reacción con la familia, la colectividad y la naturaleza, ${ }^{9}$ lo que garantiza la reproducción social perpetua, en la medida en que se sobrepone al caos. ${ }^{10}$

Que la especie humana puede convivir como una gran familia es una posibilidad y un ideal para Confucio, ya que no es otro el mandato del cielo. Su pedagogía, en la medida en que está abierta a todos los pueblos, abandona cualquier sesgo chovinista para erigirse como una doctrina cosmopolita que alienta la diversidad de culturas y modalidades de organización política, con el requisito del acuerdo sobre lo básico, a saber, la pedagogía de las autoridades para identificar y estimular las virtudes ciudadanas. Las libertades son concomitantes con las demás virtudes, pues "cuando el Estado está bien gobernado se puede actuar y hablar con osadía, cuando está mal gobernado se puede actuar con osadía, pero hay que hablar con prudencia" (Confucio, 1995, p. 23). Por eso mismo, el deber oficial de educar (Confucio, 1995, p. 89) consiste en facilitarle a todo el mundo la vida pública, práctica que deja traslucir lo mejor de cada persona y la habilita para exigir la rectitud de las autoridades mediante los mecanismos de la rendición de cuentas: "Cuando el mundo está bien gobernado, los ritos, la música y las expediciones militares proceden del Hijo del Cielo", de lo contrario, cuando la responsabilidad está depositada en seres de inferior

\footnotetext{
$9 \quad$ Hay un tránsito entre la virtud personal y la virtud colectiva. Son las mismas: "el hombre vulgar, cuando está en privado hace toda clase de males, pero cuando ve a un hombre superior disimula, esconde su mal y muestra su bien, pero si el otro lo ve como si observara sus entrañas, ¿cuál es la utilidad? Esto es lo que significa la frase: la sinceridad del interior aparece en el exterior" (Confucio, 1995, p. 329).

10 Dice Confucio: "Me disgusta que el morado le quite su brillo al rojo, que los ritmos zheng confundan la música ya y que las bocas aprovechadas se dediquen a derribar dinastías y hundir Estados" (Confucio, 1995, p. 125).
} 
categoría, sin estabilidad moral, caso en que "será raro que su poder no se extinga en tres generaciones" (Confucio, 1995, p. 117).

En contraste, la edad globalizada actual ha llevado a su máxima expresión la estrategia política afín a la ideología individualista heredera del paradigma lutero-cartesiano. En ella, el yo autorreferencial legitima la iniciativa privada y el éxito individual en la actividad económica, primero para el correspondiente premio en la otra vida, según Max Weber (2001), hoy día por motivos más terrestres y psicológicos de la acumulación per se. Las estructuras comunitarias aparecen recusables en razón de la pérdida de eficiencia en los procesos productivos frente al sistema de investigación y producción masiva de bienes y necesidades artificiosas. El modelo pedagógico mejor adaptado ha de responder a la reproducción creciente del capital, su función es la de cooperar con ese objetivo fundamental, por medio de la instrucción intensa a cada individuo como agente productivo-consumidor y, si no productivo, ipor lo menos consumidor! Los diversos componentes de la vida social han de estar acoplados de tal manera en la estrategia educativa, que el sujeto sea el más apto para cooperar con la valorización del inversionista. En apariencia, el capitalismo centra su atención en el individuo, pero no es así: el centro legitimador de la acción humana es la extrahumana reinvención constante del capital.

La organización política del capitalismo globalizado corresponde a esa idea de democracia, como explica Badiou (2010), donde el lema igualitario se convierte también en preciado objeto de consumo y de diferenciación política internacional entre los pueblos "civilizados", "democráticos", liberales y los atrasados, con regímenes autoritarios. Para enmendar los disparates, algunos autores oponen a la democracia liberal la "democracia pragmática" asiática, más afín con la regulación económica por parte del Estado (O’Dwyer, 2001). Sin embargo, un juego de palabras de este porte no remedia mayor cosa, ya que se trata de un desbarajuste mundial, sincrónico, en una etapa de la historia cuyo fin último pareciera ser el máximo deterioro ecológico y humano en el menor tiempo posible, por el simple dictado de la valoración del capital financiero, dependiente de la velocidad de su rotación. 
En Confucio, tal materialización de la existencia humana evidencia un despropósito, debido a que el trabajo, la valentía y la lucha por la sobrevivencia han de estar ligados a la búsqueda de la verdad y a la práctica de la bondad durante la vida. Se trata de una vida larga y grata, en el disfrute de la compasión, la sabiduría y el trabajo de los demás, como los baluartes de la convivencia comunitaria. En la educación para la formación de las virtudes parece guardarse el enigma de la vida grata. La mayor realización personal, familiar y de la comunidad política es proporcional a la calidad moral de las personas y las normas que las componen. Estamos ante un modelo educativo divergente de la estrategia educativa instrumental para la simple apreciación del capital.

Afianzada como lo ha estado en ciertas sociedades asiáticas, la marca del confucianismo promete ideas y experiencias orientadas hacia la globalización del trato digno, respetuoso e incluyente de toda la familia humana, por el simple hecho de ser cada uno un ser único capaz de desplegar su potencialidad en el aprendizaje de las virtudes (Ackerly, 2005), base de la democracia genuina. Este tipo de sociedad tiene como referencia la armonía general, un objetivo que contraviene el uso ambiental irresponsable y la cosificación de las relaciones humanas. En el diálogo y acuerdo con otros paradigmas alternativos reside la universalidad que se espera del confucianismo (Zhao, 2008) y su renovado aporte al humanismo planetario por medio de la educación.

\section{Conclusión}

En la tarea de desentrañar la pedagogía confuciana se hace necesario superar algunas barreras levantadas en su contra. La apreciación de su filosofía es ambigua, incluso en la propia sociedad china en la que se desenvolvió y que, por cierto, sería la primera beneficiaria de su pensamiento. En efecto, con base en los exámenes de Estado del "ejercicio octópodo" (resumen de filosofía confuciana en ocho acápites), el imperio se nutrió con las enseñanzas de los espíritus más cultivados, para dar lugar a una meritocracia sin par, base de una organización política que se sostuvo por más de 2000 años, hasta el siglo XIX, cuando el Ejército real y el opio de los ingleses derrumbó tan preciado monumento inmaterial. Junto con la decadencia de la dinastía, su doctrina inspiradora perdió crédito y, con el fin de rescatar a China del yugo 
colonialista, Mao atacó al confucianismo durante la Revolución Cultural de los años sesenta. Una vez reconciliado con esa sabiduría, hoy día el Gobierno chino la convierte en el estandarte de su soft power global. Aquella censura maoísta fue uno de los tantos obstáculos que ha debido sortear el planteamiento del sabio de la armonía comunitaria.

No sin razón Confucio entra en la discusión pedagógica contemporánea. La disputa sobre los conflictos se suele centrar en los asuntos periféricos de la estrategia y de la competencia de poderes económicos y militares, pero se soslaya la apuesta ética de la vida social. El credo liberal de los derechos o las libertades negativas cubre con su velo la realidad de la coerción ideológica y física que lleva a cabo para imponer un ordenamiento planetario plutocrático. Contrarrestar el subjetivismo metodológico con el paradigma de la sabiduría, la reciprocidad y la valentía viene a ser una propuesta estimulante en la búsqueda de alternativas a la formación humana, más allá del adiestramiento para la sociedad del consumo masificado y el uso instrumental del otro.

El confucianismo es una doctrina moral eudemonista, basada en la comprensión y la práctica de las virtudes, con el fin de compaginar las opciones de realización personal con el orden social y cósmico preestablecido. Ese encadenamiento entre los seres humanos puede ser más o menos armónico y, en la medida en que lo es, responde a las orientaciones del todo, del tien y su tao (sus reglas), pero cuando se aparta de ellas debe ser cambiado. Quienes están llamados a realizar esos cambios en la sociedad son los mismos que deben regentarla; se trata de los hombre superiores, de los mejores. Ellos son quienes acumulan más virtudes a lo largo de la vida, en esencial tres: sabiduría, valentía y humanitarismo. En principio, cualquier persona puede lograrlo, pero en la realidad no todos lo alcanzan, debido a que aún no tienen la experiencia que da el recorrido de los años o no han contado con la fortuna de tener un maestro. De ahí la importancia de la familia, porque ella no es tan solo el medio en donde nacemos y recibimos los cuidados como seres indefensos, sino la primera escuela para aprender los códigos sociales, el lenguaje y las pautas para alcanzar una existencia larga y feliz. 
Entre las claves de la socialización de los niños está el lenguaje o, mejor, en el lenguaje está la clave de la socialización de los niños. El niño aprende que cada hecho, cada cosa y, sobre todo, cada persona responde a un nombre. La responsabilidad es conseguir la concordancia entre el nombre y la acción. No son roles fijos, cambian con el tiempo, pero en cada uno la persona está acoplada a códigos que debe respetar; de este modo, de la palabra niño se espera que quien la porte tenga conducta de niño y no de adulto y ser padre o madre tiene otras implicaciones, lo mismo que hermano mayor o hermano menor, policía, profesor, médico o campesino. La pedagogía del humanismo confuciano facilita moldear la individualidad a partir de la conciencia de las relaciones recibidas o tomadas y de la capacidad de ubicarse en un término medio, justo, entre el dato natural y el perfilamiento cultural. Desecha cualquier automatismo para rescatar el potencial de decidir lo correcto, con plena voluntad, con disciplina y con el gozo de compartir el tao, como empresa colectiva y armoniosa. Contrasta, por eso, con los modelos contractuales del Estado de las doctrinas liberales, erigido como instancia superior encargada de reprimir la barbarie humana.

\section{Referencias bibliográficas}

Ackerly, B. A. (2005). Is Liberalism the Only Way toward Democracy? Confucianism and Democracy. Political Theory, 33 (4), 547-576 .

Adler, J. A. (2011). Confucianism in China Today. Recuperado de http://www2. kenyon.edu/Depts/Religion/Fac/Adler/Writings/Confucianism\%20 Today.pdf

Aristóteles. (2003). Ética nicomáquea. En Aristóteles, Ética nicomáquea/Ética eudemia. (pp. 128-408). Madrid: Gredos.

Badiou, A. (2010). L'emblème démocratique. En G. E. Agamben, A. Badiou, D. Bensaï, W. Brown, J. L. Nancy, J. Rancière et al., Démocratie dans quel état? (pp. 15-24). París: La Fabrique.

Bartram, D. (2005). The Great Eight Competencies: A Criterion-Centric Approach to Validation. Journal of Applied Psychology, 90 (6), 1185-1203. Boreham, N. (2004). A Theory of Collective Competence: Challenging the Neo-Liberal Individualisation of. British Journal of Educational Studies, $52(1), 5-17$. 
Boud, D. (2000). Sustainable Assessment: Rethinking Assessment for the Learning Society. Studies in Continuing Education, 22 (2), 151-167.

Confucio. (1995). Los cuatro libros. (J. Pérez Arroyo, trad.). Madrid: Alfaguara. De Bary, T. (1984). Neo-Confucian Education and Post-Confucian East Asia. Bulletin of the American Academy of Arts and Sciences, 37 (5), 7-17.

De Gregori, W. (2011). Manifiesto de la proporcionalidad con democracia directa. Raleigh: Lulu Enterprises.

Descartes, R. (1981). Discurso del método, Dióptrica, meteoros y geomería. (G. Quintás Alonso, trad.). Madrid: Alfaguara.

Dierckxsens, W. (1981). Política y población. San José: Universitaria Centroamericana.

Fox, R. A. (1997). Confucian and Communitarian Responses to Liberal Democracy. The Review of Politics, 59 (3), 561-592.

Fung, Y.-L. (1976). A Short History of Chinese Philosophy. Nueva York: The Free Press.

Gulikers, J. B. (2009). Developer, Teacher, Student and Employer Evaluations of Competence-Based Assessment Quality. Studies in Educational Evaluation, 35 (2-3), 110-119.

Hayton, J. C. (2006). A Competency-Based Framework for Promoting Corporate Entrepreneurship. Human Resource Management, 45 (3), 407-427.

Hu, W. (2007). On Confucian Communitarianism. Frontiers of Philosophy in China, 2 (4), 475-487.

Jung, H. Y. (1993). Confucianism as Political Philosophy: A Postmodern Perspective. Human Studies, 16 (1/2), 213-230.

Klein, N. (2013). Por qué necesitamos una eco-revolución. Recuperado de http:/ / viva.org.co/cajavirtual/svc0378/articulo18.htmKe

Leibniz, G. W. (1983). Monadología. Discurso de metafísica. La profesión de fe del filósofo. Barcelona: Orbis.

Martin, A. (2009). Interpersonal Relationships, Motivation, Engagement, and Achievement: Yields for Theory. Review of Educational Research, 79 (1), 327-365.

Marx, K. (1975). El capital. Crítica de la economía política. (W. Roces, trad.). México D. F.: Fondo de Cultura Económica.

Maslow, A. (1943). A Theory of Human Motivation. Psychological Review, 50 (4), 370-396.

McClelland, D. (1973). Testing for Competence rather than for 'Intelligence'. American Psychologist, 28 (1), 423-447. 
Mehta, J. (2013). From Bureaucracy to Profession: Remaking the Educational Sector for the Twenty-First Century. Harvad Educational Review, 83 (3), 463-488.

Mohrman, K. (2013). Are the Chinese Universities Globally Competitive? China Quarterly, 215 (3), 727-743.

Morin, E. (2000). Introducción al pensamiento complejo. Barcelona: Gedisa.

O’Dwyer, S. (2001). Democracy and Confucian Values. Philosophy East and West, 53 (1), 39-63.

Rancière, J. (2006). Hatred of Democracy. Londres: Verso.

Rancière, J. (2010). El maestro ignorante. Cinco lecciones sobre la emancipación intelectual. Barcelona: Laertes.

Sim, S.-F. (2001). Asian Values, Authoritarism and Capitalism in Singapore. The Public, 8 (2), 45-66.

Taylor, C. (1997). Argumentos filosóficos. Barcelona: Paidós.

Tugendhat, E. (1998). Ser-verdad-acción: ensayos filosóficos. Barcelona: Gedisa.

Wallerstein, I. (1974). The Rise and Future Demise of the World Capitalist System: Concepts for Comparative Analysis. Comparative Studies in Society and History, 16 (4), 387-415.

Wang, Q. J. (1999). The Golden Rule and Interpersonal Care: From a Confucian Perspective. Philosophy East and West, 49 (4), 415-438.

Wang, Y. (2008). Confucian Ethics and Emotions. Frontiers of Philosophy in China, 3 (3), 352-365.

Weber, M. (2001). La ética protestante y el espiritu del capitalismo. Madrid: Alianza. Zhao, T. (2008). The Self and the Other: An Unanswered Question in Confucian Theory. Frontiers of Philosophy in China, 3 (2), 163-176. 